\title{
Early experience of stereotactic biopsy of brain lesion in tertiary centre of Nepal
}

\author{
Binit Kumar Jha $M S^{1}$, Prabhat Jha $M S^{2}$, Rajiv Jha $M C h^{3}$, Prakash Bista $M C h^{4}$ \\ 1,2,3,4 National Neurosurgical Referral Center, National Academy of Medical Sciences, Kathmandu, Nepal
}

\section{Abstract}

Background: Stereotactic surgery or stereotaxy is a minimally invasive form of surgical intervention which makes use of a three-dimensional coordinate system to locate small targets inside the body and to perform on them some procedures such as ablation, biopsy, lesion, injection, stimulation, implantation, radiosurgery (SRS), etc. Though it was developed a long time ago as a useful adjunct to brain lesions evaluation, it's use at our centre is quite recent. Methodology: The study included eight patients who underwent frame based stereotactic biopsy and pathological evaluation of specimen at National Academy of Medical Sciences (NAMS).

Results: Out of eight patients the results were positive in seven patient and negative in one patient.

Conclusions: The basic advantages of stereotaxy were realized in our cases with minimal morbidity and no mortality. Craniotomy for biopsy could be avoided.

Key words: Brain biopsy, Stereotaxy

\section{Introduction}

$\mathrm{S}_{\mathrm{i}}^{\mathrm{s}}$ tereotactic surgery or stereotaxy is a minimally invasive form of surgical intervention. ${ }^{1,2}$ It makes use of a three-dimensional coordinate system to locate interventions such as injection, stimulation, implantation, radiosurgery (SRS). ${ }^{3-6}$ It uses either with a "frame" or "frameless" system, depending on the surgeon's

Access this article online
Website: https://www.nepjol.info/index.php/NJN
DOI: https://doi.org/10.3126/njn.v18i1.31822
HOW TO CITE
Jha BK, Jha P, Jha R, Bista P. Early experience of stereotactic
biopsy of brain lesion in tertiary centre of Nepal. NJNS.
$2021 ; 18(1): 51-56$.

'ORCID id: 0000-0002-0844-2538

${ }^{2}$ ORCID id: 0000-0001-5504-5917

${ }^{3}$ ORCID id: 0000-0002-2830-7835

${ }^{4}$ ORCID id: 0000-0002-4811-6964

\author{
Address for correspondence: \\ Dr. Binit Kumar Jha, \\ MCh Neurosurgery Resident, \\ National Neurosurgical Referral Center, \\ National Academy of Medical Sciences, Kathmandu, Nepal \\ E-mail: binitjha.95@gmail.com \\ Phone: +977-9851220978
}

Copyright (C) 2021 Nepalese Society of Neurosurgeons (NESON)

ISSN: 1813-1948 (Print), 1813-1956 (Online) preference and the location and size of the lesion. It was first used in 1908 by Sir Victor Horsley and Robert Clarke who specified the use of a Cartesian coordinate system. 5,6 First application of "modern" frame-based stereotaxy to humans was used by Spiegel and Wycis in 1947.7

For a frame based stereotaxy, a frame is attached to the patient's head. Then an imaging, a CT or MRI, is done to find out the exact position of the lesion with respect to the different points in the frame. ${ }^{8}$ Then the data is entered into a software and the exact location of the lesion in three different coordinates is calculated, using which, biopsy is later performed. ${ }^{8,9}$

For a frameless biopsy MRI or CT image is imported into a computer system that provides a 3-dimensional image of brain and biopsy target in the operating room. This image is used along with a biopsy guidance arm to guide needle safely into the target. ${ }^{10,11}$

Both approaches have the same safety and success record. The main advantage of frame based stereotaxy is that the rigid metal frame serves to maintain a fixed threedimensional coordinate system. ${ }^{8-11}$ But the bulky assembly of the frame limits head positioning and physically interferes with performing a craniotomy. The arc assembly for aiming is non-intuitive, non-interactive, and limited to a single trajectory at a time. Consequently, framed based systems are reserved for procedures such as needle biopsy or placement of depth electrodes. The success rate for obtaining a definitive diagnosis is $>95 \%$, but depends on the type of pathology. ${ }^{8-11}$

In general, the diagnostic success rate is high. It is either performed to confirm a suspected brain lesion when 


\section{Jha et al}

resection is not considered appropriate or when a highgrade tumor is suspected on imaging or when a wide-range of differential diagnosis is present for a suspected tumor. ${ }^{8}$ It is contraindicated in very small lesions and in patients who have coagulation disorder. The risk of procedure is bleeding which can present with mild headache to a stroke, coma, or even death. The risk of bleeding following biopsy is around $5 \%$ and mortality is around $1 \%$. Besides bleeding, infection and seizure may occur. ${ }^{9-12}$

This study shares the early experience of frame based stereotactic biopsy at National Neurological Referral Center, Bir Hospital.

\section{Methodology}

This is a prospective observational study conducted in the Department of Neurosurgery, National Neurological Referral Center, National Academy of Medical Sciences, Bir hospital. Data were collected from the patients' hospital records. The first frame based stereotactic biopsy was performed on 2075/04/01 and up to 2077/08/10 eight cases have been performed. The cases were selected for the biopsy primarily based upon the location of lesion (either deeper location or eloquent areas). No cases were excluded.

Basic principles that are applied when planning a trajectory to target include

- The instrument's trajectory should avoid eloquent brain and breach only one pial surface to minimize the chance of haemorrhage. This is particularly true for lesions near the sylvian fissure or pineal region.

- When possible, the instrument should penetrate the brain parallel to white matter tracts, especially when interested in brainstem lesions.

- Generally, the majority of the cerebrum, basal ganglia, thalamus, and brainstem can be approached with entry points anterior to the coronal suture. For lesions in the occipital, parietal, temporal lobe or the pineal region, a superior parieto-occipital approach is better. Temporal lesions may, additionally, be approached laterally and cerebellar lesions approached posteriorly.

Our hospital has a Cosman-Roberts-Wells (CRW) frame based system. This system uses a Cartesian coordinate system, the $\mathrm{x}$ - and $\mathrm{y}$-axes refer to a mediallateral and anterior-posterior location, respectively, whereas the $\mathrm{z}$-axis refers to a base-vertex location. Many methods have been outlined to determine the $\mathrm{z}$-axis, but the most popular method uses posts with an "N" shape configuration where the position of the oblique rod relative to the vertical rods defines the $\mathrm{z}$ plane of the slice ${ }^{[3]}$. Once the target is localized, the arc method is used to direct a probe to the selected target and carry out the remainder of the procedure. The basic steps of the procedure at our center are as follows:

1. Frame Application

Frame application is performed in the operating room with the patient in the sitting position. [Figure 1] Our preference is to sterilize the scalp with an alcohol or betadine $5 \%$ prep without shaving hair. The assistant stands either behind or on the side of the patient and stabilizes the ring. The ring should be applied parallel to the cranial floor through the use of ear bars, but some frame parallax is acceptable. We anesthetize the scalp and periosteum with $2 \%$ xylocaine and adrenaline. We prefer to place the two posterior pins first and then we place the anterior pins and hand tighten all four pins, before using the wrench, with a two-fingers method. Then the patient is taken for imaging.

\section{Target Localization for Stereotactic Biopsy}

CT brain is the imaging modality of choice at our center. With the patient still in the scanner, it is important to ensure that all fiducial markers are visible on all images. We obtain fiducial and target coordinates in all three orthogonal planes and average the three paired coordinates with the greatest spatial accuracy, eliminating the coordinate in each orthogonal plane which is, by definition, less accurate because of volume averaging.

3. Stereotactic frame attachment

The CRW Stereotactic system is then attached over the frame [Figure 2].

4. Identifying the lesion on the stereotactic system The arc system directs a stereotactic probe isocentrically around the designated target, thus obviating a fixed entry point. The Cosman-RobertsWells (CRW) system included some of the same design elements as the BRW system, including a phantom frame, the same CT localizer, and the same probe depth fixed at $16 \mathrm{~cm} .^{7,8}$ New innovations include the introduction of MRI-compatible frames and localizers, and versatility in arc-to-frame applications that enabled inferior trajectories into the posterior fossa or lateral routes into the temporal lobe. Additionally, this system included a phantom base onto which the stereotactic frame including the arc could be placed to test the accuracy of the settings.

The localizer unit is secured to the ring with three ball- 


\section{Stereotactic biopsy of brain lesion}

and-socket interlocks and consists of six vertical posts and three diagonal posts, creating an " $\mathrm{N}$ " shaped appearance. It is this latter " $\mathrm{N}$ " construct that establishes the axial CT plane relative to the skull base by calculating the relative distance of the oblique to the vertical rods. Target coordinates are established by first identifying the axial slice that best features the lesion. The $\mathrm{x}$ and $\mathrm{y}$ coordinates for each of the nine fiducial rods are identified on the CT or MRI monitor, as are the $\mathrm{x}$ and $\mathrm{y}$ coordinates for the target. All coordinates are entered into a laptop computer (the SCSI), which computes the target co-ordinates. For institutions with the Radionics OTS frameless image guidance system, target and trajectory calculations can now be performed with the OTS intraoperative workstation, which provides more flexibility than the SCSI laptop.

\section{Results}

The first case was performed in 2075/04/01. A total of eight cases have been included in this study. The histopathology reports were conclusive in six cases and was inconclusive in one case. Deep lesions in thalamus were biopsied in three cases. Other cases had lesions in frontal or temporal lobes (table 1).

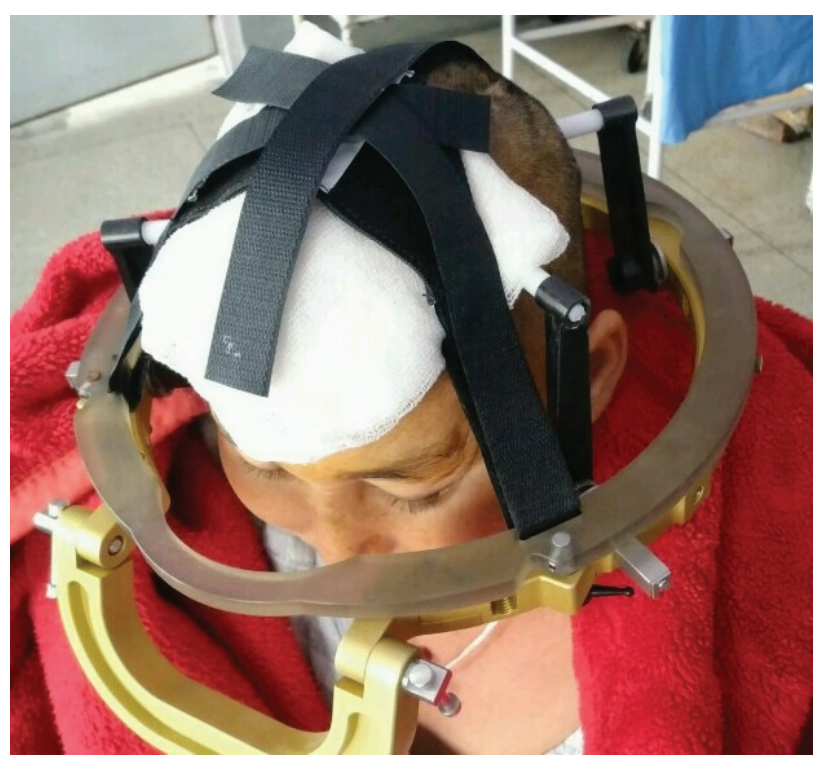

Figure 1: Preoperative frame placement

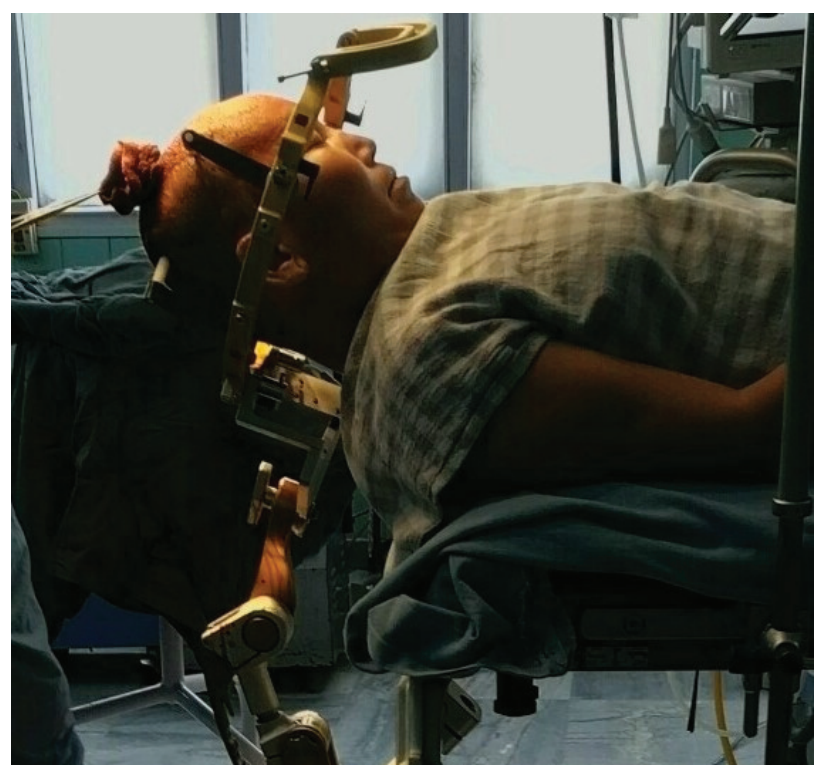

Figure 2: Intraoperative image
Diagnosis requiring biopsy<smiles>C1CCCCC1</smiles>

Preoperative planning<smiles>C1CC2CCC1C2</smiles>

Stereotactic frame attached to the patient in operation theatre<smiles>C1CC2CCC1C2</smiles>

CT head done with frame attached to the patient<smiles>C1CC2CCCC2C1</smiles>

CT data entered into software and coordinates of the lesion calculated and point of entry identified

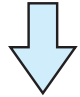

CRW frame set up according to the coordinates calculated from the software

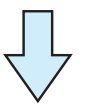

The position of the lesion reconfirmed in a phantom

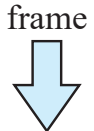

CRW frame attached to patients head

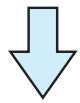

Burr hole and biopsy

Figure 3. Road map of frame based stereotactic biopsy 


\begin{tabular}{|c|c|c|c|c|}
\hline History & Examination & Imaging & Biopsy & Biopsy report \\
\hline $\begin{array}{l}42 \mathrm{yr} / \mathrm{F} \text { from Bhaktapur } \\
\text { Headache and vomiting for } 4 \\
\text { months }\end{array}$ & $\begin{array}{l}\text { Sensation decreased } \\
\text { over } \mathrm{C} 6 \text { to } \mathrm{T} 1 \\
\text { over right side rest } \\
\text { normal }\end{array}$ & $\begin{array}{l}\text { Left temporal lobe } \\
\text { lesion }\end{array}$ & $\begin{array}{l}\text { Left temporal lobe } \\
\text { burrhole biopsy }\end{array}$ & $\begin{array}{l}\text { Anaplastic } \\
\text { astrocytoma, NOS } \\
\text { (WHO grade III) }\end{array}$ \\
\hline $\begin{array}{l}13 \mathrm{yr} / \mathrm{F} \text { from Butwal } \\
\text { Multiple episodes of } \\
\text { abnormal body movement } \\
\text { since one and half year. }\end{array}$ & Grossly normal & ICSOL left temporal & $\begin{array}{l}\text { Left temporal lobe } \\
\text { lesion }\end{array}$ & $\begin{array}{l}\text { Tiny fragment of } \\
\text { glial tissue only }\end{array}$ \\
\hline $\begin{array}{l}50 \mathrm{yr} / \mathrm{F} \text { from Dolakha } \\
\text { Frontal headache } \\
\text { Loss of consciousness for } 30 \\
\text { minutes ten days back }\end{array}$ & Grossly normal & $\begin{array}{l}\text { Left frontal lobe } \\
\text { lesion }\end{array}$ & $\begin{array}{l}\text { Left frontal lobe } \\
\text { tissue biopsy }\end{array}$ & $\begin{array}{l}\text { Diffuse astrocytoma } \\
\text { (WHO Grade II) }\end{array}$ \\
\hline $\begin{array}{l}26 \mathrm{yr} / \mathrm{M} \text { from Biratnagar } \\
\text { On and off headache for } 10 \\
\text { years }\end{array}$ & Within normal limit & $\begin{array}{l}\text { Lesion in right basal } \\
\text { ganglia involving } \\
\text { thalamus, right side } \\
\text { of midbrain and right } \\
\text { ophthalmic tract }\end{array}$ & $\begin{array}{l}\text { Stereotaxy and } \\
\text { biopsy }\end{array}$ & Negative \\
\hline $\begin{array}{l}20 \mathrm{yr} / \mathrm{F} \text { from Kathmandu } \\
\text { Abnormal body movement } \\
\text { for } 5 \text { months }\end{array}$ & Grossly normal & $\begin{array}{l}\text { Right frontal lobe } \\
\text { mass }\end{array}$ & $\begin{array}{l}\text { Biopsy frontal lobe } \\
\text { mass }\end{array}$ & $\begin{array}{l}\text { Consistent with } \\
\text { diffuse astrocytoma } \\
\text { (Grade II) }\end{array}$ \\
\hline $\begin{array}{l}52 \mathrm{yr} / \mathrm{F} \text { from Syangja } \\
\text { Weakness of left upper and } \\
\text { lower limb for } 2 \text { months with } \\
\text { left sided headache }\end{array}$ & $\begin{array}{l}\text { Power } 4 / 5 \text { in left } \\
\text { upper and lower } \\
\text { limb }\end{array}$ & $\begin{array}{l}\text { Left sided thalamic } \\
\text { glioma }\end{array}$ & Biopsy thalamus & $\begin{array}{l}\text { Compatible with } \\
\text { diffuse astrocytoma } \\
\text { (WHO grade II) }\end{array}$ \\
\hline $\begin{array}{l}35 \mathrm{yr} / \mathrm{M} \text { from Baitadi } \\
\text { Left sided body pain } \\
\text { Loss of consciousness } \\
\text { Weakness of left half of body } \\
\text { Unable to speak properly }\end{array}$ & $\begin{array}{l}\text { Power right and left } \\
\text { lower limb } 1 / 5, \text { left } \\
\text { V1 cranial nerve } \\
\text { palsy }\end{array}$ & $\begin{array}{l}\text { Right thalamic } \\
\text { tumor bleed with } \\
\text { hydrocephalus }\end{array}$ & Biopsy thalamus & $\begin{array}{l}\text { Glioblastoma (WHO } \\
\text { Grade IV) }\end{array}$ \\
\hline
\end{tabular}

Table 1: Details of cases

\section{Discussion}

Since the introduction of stereotaxy it has been a great help for neurosurgeons. ${ }^{5-7}$ Our centre uses the CRW system which is the most modern form of frame-based biopsy. As the volume of cases increases and the experience of surgeon increases it can be utilized as a regular tool at our centre as well.

Biopsy was positive in all except for one. This could have been because of deeper location of the lesion and sampling error. The main reason to prefer stereotactic biopsy over an open operative procedure is that stereotactic procedures have a higher rate of diagnostic accuracy and minimal adverse effects. ${ }^{7-9}$ Stereotactic biopsy is preferred over open biopsy in tumours with characteristics which include (1) lesions that do not exert symptomatic mass effect or are not treatable by surgical excision, such as metastases or malignant intrinsic brain tumours (2) deepseated lesions or those occupying space in eloquent cortical regions or deep nuclei (e.g., basal ganglia, thalamus), for which open resection would lead to unacceptable morbidity or mortality; and (3) infiltrative lesions (e.g., gliomatosis cerebri) that do not have a clear brain-tumour margin and are unlikely to be excised without significant loss of normal brain parenchyma. Besides if the lesion's appearance on imaging or the course of the disease suggest an alternative pathology, such as an infectious or demyelinating process, stereotactic biopsy is an appropriate first step rather than a large open procedure. ${ }^{12-15}$

Relative contraindications are vascular tumours such as metastatic renal cell carcinoma, choriocarcinoma, or metastatic melanoma. If suspected, these should not be 
approached stereotactically, because of inherently higher risk for hemorrhage. ${ }^{16}$ In cases of metastatic tumours, effort should be made to find the primary neoplasm. Besides, tumours close to major blood vessel, the vesselrich sylvian fissure, the cavernous sinus, or the brainpial border should alert the neurosurgeon to the risk for haemorrhage. Stereotactic biopsy should also be avoided, when possible, in patients treated with anti-platelets or anticoagulant drugs.

Sampling error is a concern with stereotactic biopsies, particularly with non-enhancing lesions, such as lowgrade gliomas. ${ }^{5-7}$ An inherent limitation of stereotactic biopsy localization is that the surgical coordinates are based on information obtained from preoperative imaging. A number of factors can lead to mis-registration of stereotactic coordinates on imaging with actual physical location. Intraoperative fluid shifts or brain displacement after dural opening is the largest source of anatomic alteration that leads to ambiguity within the navigational system. When such frame shifting occurs, diagnostic yield and accuracy are less probable. In an effort to avoid this problem, we avoid large dural openings and insert biopsy needles through the smallest possible bone and dural opening. ${ }^{15,16}$

The most common complication of stereotactic biopsy is intracranial haemorrhage, which frequently results from damage to blood vessels in the trajectory of the biopsy needle or at the biopsy site itself. ${ }^{11,12}$ Current navigation systems with the trajectory view allow trajectory planning to avoid crossing sulcal and pial surfaces and to avoid blood vessels. Second, damage to pathologically friable vessels within the targeted neoplastic lesion can also account for hemorrhagic complications. Reported rates of haemorrhage during stereotactic biopsy procedures range from $0 \%$ to $11.5 \% \cdot{ }^{13-15} \mathrm{~A}$ second, less frequent complication of stereotactic biopsy is a new neurological deficit caused by trauma to the surrounding brain parenchyma as a result of direct damage by the needle biopsy or the resulting edema. No major complication was reported in our cases. This could be due to the small size of sample.

\section{Conclusions}

The basic advantages of stereotaxy were realized in our cases with minimal morbidity and no mortality. Craniotomy for biopsy could be avoided.

Conflict of Interest: None

Source(s) of support: None

\section{References}

1. Principles of Stereotaxy. Chapter 2 of Ganz, J. Gamma Knife Neurosurgery, Springer, 2011.

2. Rahman, Maryam; Murad, Gregory J. A.; Mocco, J (September 2009). "Early history of the stereotactic apparatus in neurosurgery". Neurosurgical

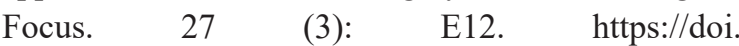
org/10.3171/2009.7.FOCUS09118

3. Solberg, Timothy D.; Siddon, Robert L.; Kavanagh, Brian (2012). "Chapter 1: Historical Development of Stereotactic Ablative Radiotherapy". In Lo, Simon S.; Teh, B.S.; Lu, J.J.; Schefter, T.E. Stereotactic body radiation therapy. Berlin: Springer. pp. 9-35. https:// doi.org/10.1007/174_2012_540

4. Kandel EI, Schavinsky YV. Stereotaxic apparatus and operations in Russia in the 19th century. J Neurosurg. 1972 Oct;37(4):407-11. https://doi.org/10.3171/ jns.1972.37.4.0407

5. Willems PW, Taphoorn MJ, Burger H, Berkelbach van der Sprenkel JW, Tulleken CA. Effectiveness of neuronavigation in resecting solitary intracerebral contrast-enhancing tumors: a randomized controlled trial. J Neurosurg. 2006 Mar;104(3):360-8. https:// doi.org/10.3171/jns.2006.104.3.360

6. Spiegel EA, Wycis HT, Marks M, Lee AJ. Stereotaxic Apparatus for Operations on the Human Brain. Science. 1947 Oct 10;106(2754):349-50. https://doi. org/10.1126/science.106.2754.349

7. Gildenberg PL. Spiegel and Wycis - the early years. Stereotact Funct Neurosurg. 2001;77:11-16. https:// doi.org/10.1159/000064587

8. Dorward NL, Paleologos TS, Alberti O, Thomas DG. The advantages of frameless stereotactic biopsy over frame-based biopsy. $\mathrm{Br}$ J Neurosurg. 2002 Apr;16(2):110-8. https://doi. org/10.1080/02688690220131705

9. Woodworth G, McGirt MJ, Samdani A, Garonzik I, OliviA, Weingart JD. Accuracy of frameless and framebased image-guided stereotactic brain biopsy in the diagnosis of glioma: comparison of biopsy and open resection specimen. Neurol Res. 2005 Jun;27(4):35862. https://doi.org/10.1179/016164105X40057

10. Woodworth GF, McGirt MJ, Samdani A, et al. Frameless image guided stereotactic brain biopsy procedure: diagnostic yield, surgical morbidity, and comparison with the frame-based technique. J Neurosurg. 2006;104:233-237. https://doi. org/10.3171/jns.2006.104.2.233

11. Quiñones-Hinojosa A, Ware ML, Sanai N, McDermott MW. Assessment of image guided accuracy in a skull model: comparison of frameless stereotaxy techniques 


\section{Jha et al}

vs. frame-based localization. J Neurooncol. 2006 Jan;76(1):65-70. https://doi.org/10.1007/s11060-0052915-z

12. Kongkham PN, Knifed E, Tamber MS, Bernstein M. Complications in 622 cases of frame-based stereotactic biopsy, a decreasing procedure. Can J Neurol Sci. 2008 Mar;35(1):79-84. https://doi. org/10.1017/s0317167100007605

13. Jackson RJ, Fuller GN, Abi-Said D, et al. Limitations of stereotactic biopsy in the initial management of gliomas. Neuro Oncol. 2001;3(3):193-200. https:// doi.org/10.1093/neuonc/3.3.193
14. McGirt MJ, Villavicencio AT, Bulsara KR, Friedman AH. MRI-guided stereotactic biopsy in the diagnosis of glioma: comparison of biopsy and surgical resection specimen. Surg Neurol. 2003 Apr;59(4):277-81. https://doi.org/10.1016/s0090-3019(03)00048-x

15. McGirt MJ, Woodworth GF, Coon AL, Frazier JM, Amundson E, Garonzik I, Olivi A, Weingart JD. Independent predictors of morbidity after imageguided stereotactic brain biopsy: a risk assessment of 270 cases. J Neurosurg. 2005 May;102(5):897-901. https://doi.org/10.3171/jns.2005.102.5.0897

16. Coffey RJ, Lunsford LD. Stereotactic surgery for mass lesions of the midbrain and pons. Neurosurgery. 1985;17:12-18. https://doi.org/10.1227/00006123198507000-00003 